\title{
Correlation of von Willebrand factor gene polymorphism and coronary heart disease
}

\author{
AI-GUO XU ${ }^{1}$, RONG-MEI XU ${ }^{2}$, CHANG-QING LU ${ }^{3}$, MENG-YING YAO $^{1}$, WEI ZHAO ${ }^{1}$, \\ $\mathrm{XIN} \mathrm{FU}^{1}$, JING GUO ${ }^{1}$, QIN-FU XU ${ }^{1}$ and DAN-DAN LI ${ }^{1}$ \\ ${ }^{1}$ Department of Respiratory and Critical Care Medicine, The First Affiliated Hospital of Zhengzhou University, \\ Zhengzhou, Henan 450052; ${ }^{2}$ Human Science Laboratory, Institute of Physical Education of Henan Polytechnic University, \\ Zhengzhou, Henan 454000; ${ }^{3}$ Department of Laboratory Medicine, The Second Affiliated Hospital, \\ Henan University of Traditional Chinese Medicine, Zhengzhou, Henan 450052, P.R. China
}

Received May 25, 2012; Accepted August 9, 2012

DOI: $10.3892 / \mathrm{mmr} .2012 .1037$

\begin{abstract}
To characterize von Willebrand factor (vWF) gene polymorphisms at site A1381T and the correlation of plasma vWF levels with coronary heart disease, the vWF genotypes at site A1381T were analyzed by polymerase chain reactionrestriction fragment length polymorphism (PCR-RFLP) in patients diagnosed with coronary heart disease and normal controls ( $n=110$ per group), and plasma vWF levels were measured by enzyme-linked immunosorbent assay. The results showed that the plasma vWF levels were higher in the experimental group than in the control group and had no association with gender $(t=11.69, \mathrm{p}<0.05)$. In the experimental group, the plasma vWF levels were higher in the patients with the AG genotype than in those with the GG genotype $(\mathrm{p}<0.05)$. In the control group, the plasma vWF levels of the subjects with blood type $\mathrm{O}$ were significantly lower than those of the individuals with other blood types $(\mathrm{p}<0.05)$. In the experimental group, all blood types had significantly higher plasma vWF levels than the control group and the difference was significant among different blood types $(\mathrm{p}<0.05)$. In summary, vWF gene polymorphisms at site A1381T were not associated with coronary heart disease, but plasma vWF levels were influenced by vWF gene polymorphisms at site A1381T, blood type and coronary heart disease.
\end{abstract}

\section{Introduction}

Von Willebrand factor (vWF) is a cytokine that is synthesized by vascular endothelial cells and stored in Weibel-Palade bodies, storage granules within endothelial cells. Upon damage to the vascular endothelium, vWF is secreted by vascular

Correspondence to: Dr Ai-Guo Xu, Department of Respiratory and Critical Care Medicine, The First Affiliated Hospital of Zhengzhou University, 1 Jianshedong Road, Zhengzhou, Henan 450052, P.R. China E-mail: zhengxuag@126.com

Key words: von Willebrand factor, polymorphism, coronary heart disease, blood type endothelial cells and is released into the plasma. The main component of $\mathrm{vWF}$ is a large multimeric glycoprotein, and its primary function is to mediate platelet adhesion and promote thrombosis (1-3). Previous studies have shown that platelet membrane glycoprotein $\mathrm{Ib}$, collagen and heparin are able to bind with the vWF gene (at the A1 domain) and affect vWF structure and function (4). The vWF gene polymorphism T/T at site A1381T markedly enhances the affinity of vWF for platelet $\mathrm{GPIb}$ (5). However, it is still unclear whether this polymorphism is related to susceptibility to coronary heart disease $(6,7)$. The current study investigated the correlation between vWF gene polymorphism at site A1381T and coronary heart disease.

\section{Materials and methods}

Study subjects. The subjects included 110 patients diagnosed with coronary arteriosclerotic heart disease in the Cardiology Department of The First Affiliated Hospital of Zhengzhou University from Oct 2009-May 2011 and comprised 62 males and 48 females. The median age of the subjects was 58.34 years (range 38-79). The control group comprised 110 healthy control subjects who received a health examination in our hospital and included 64 males and 4 females. The median age of the control group was 57.36 years (range $37-80$ ). There were no statistically significant differences in age and gender between the experimental group and the control group. All research subjects completed a health history questionnaire and received a physical examination, electrocardiogram, measurement of routine biochemical indicators and blood typing. The study was approved by the ethics committee of The First Affiliated Hospital of Zhengzhou University. All subjects provided informed consent.

Determination of plasma $v W F$ level. Plasma vWF levels were measured with an enzyme-linked immunosorbent assay kit (Sun Biotech Co., Ltd., Beijing, China). The measured result was presented as a percentage of the vWF level in the standard calibrator plasma provided in the assay kit.

Genotype identification. Polymerase chain reactionrestriction fragment length polymorphism (PCR-RFLP) was 
Table I. Plasma von Willebrand factor (vWF) levels in males and females.

\begin{tabular}{lccc}
\hline & & \multicolumn{2}{c}{ Plasma vWF level (\%) } \\
\cline { 3 - 4 } Groups & $\mathrm{n}$ & Males & Females \\
\hline Experimental & 110 & $140.41 \pm 20.05$ & $143.55 \pm 21.22$ \\
Control & 110 & $114.21 \pm 17.22$ & $108.80 \pm 16.72$ \\
\hline
\end{tabular}

Table II. Plasma von Willebrand factor (vWF) levels for genotypes $\mathrm{GG}$ and $\mathrm{AG}$.

\begin{tabular}{lccc}
\hline & & \multicolumn{2}{c}{ Plasma vWF level (\%) } \\
\cline { 3 - 4 } Groups & $\mathrm{n}$ & $\mathrm{GG}$ & $\mathrm{AG}$ \\
\hline Experimental & 110 & $133.32 \pm 12.95^{\mathrm{ab}}$ & $161.53 \pm 21.52^{\mathrm{a}}$ \\
Control & 110 & $112.86 \pm 16.74$ & $110.07 \pm 18.05$ \\
\hline
\end{tabular}

${ }^{\mathrm{a}} \mathrm{p}<0.05$ vs. control group; ${ }^{\mathrm{b}} \mathrm{p}<0.05$ vs. AG.

used to determine the polymorphism genotypes. Venous blood samples $(5 \mathrm{ml})$ were collected from all subjects. The phenol-chloroform-isopentanol method was used to extract the genomic DNA (8) and target segments were amplified by polymerase chain reaction (PCR). The sequences of the primers were: forward, 5'-CACCAGCGAGGTCTTGAAAT-3'; and reverse, 5'-GGCAAGGTCACAGAGGTAGC-3'. The PCR system was composed of: $2 \mu 1$ genomic DNA; $5 \mu 1$ 10X PCR buffer (Takara, Dalian, China); $3 \mu$ dNTP (25 mmol/; Takara); $0.5 \mu \mathrm{l}$ Taq DNA polymerase (2.5 U/ml; Takara); $3 \mu 1 \mathrm{MgCl}_{2}$ ( $25 \mathrm{mmol} / \mathrm{l}$; Takara); $1 \mu \mathrm{l}$ forward primer; $1 \mu \mathrm{l}$ reverse primer; and water to a final volume of $50 \mu \mathrm{l}$. The PCR conditions included 30 cycles of: denaturation at $94^{\circ} \mathrm{C}$ for $5 \mathrm{~min}$ as a single step; degeneration for $30 \mathrm{sec}$ at $94^{\circ} \mathrm{C}$; annealing for $45 \mathrm{sec}$ at $57^{\circ} \mathrm{C}$; extension for $60 \mathrm{sec}$ at $72{ }^{\circ} \mathrm{C}$; and a final extension for $10 \mathrm{~min}$. Digestion was carried out using $2 \mu \mathrm{l}$ PCR product, $2 \mu \mathrm{l}$ Hph I endonucleases (Promega Corporation, Madison, WI, USA), $2 \mu 1$ 10X buffer and $20 \mu 1$ deionized water. This reaction mixture was incubated in a $37^{\circ} \mathrm{C}$ water bath for $4 \mathrm{~h}$. Next, $1 \mu \mathrm{l}$ $6 \mathrm{X}$ sample buffer was added to $5 \mu \mathrm{l}$ reaction product and the total volume was loaded onto a $2 \%$ agarose gel and electrophoresed at $110 \mathrm{~V}$ for $30 \mathrm{~min}$. The genotypes were determined from the size and number of the gel bands. The genotype GG product had one band with a size of $316 \mathrm{bp}$ and the genotype AG product yielded three bands of sizes 316, 252 and $64 \mathrm{bp}$.

Statistical methods. SPSS 13.0 for Windows statistical software was used for statistical analysis using the $\chi^{2}$ test and $\mathrm{t}$-test, as appropriate. $\mathrm{p}<0.05$ was considered to indicate a statistically significant result.

\section{Results}

Correlation between gender and plasma $v W F$. The mean plasma vWF level in the experimental group $(141.78 \pm 20.53 \%)$
Table III. Genotype and allele frequency in experimental and control groups.

\begin{tabular}{lcccccc}
\hline & & \multicolumn{2}{c}{ Genotypes } & & \multicolumn{2}{c}{ Allelic gene } \\
\cline { 7 - 8 } Groups & $\mathrm{n}$ & $\mathrm{GG}$ & $\mathrm{AG}$ & & $\mathrm{G}$ & $\mathrm{A}$ \\
\hline Experimental & 110 & 77 & 33 & & 187 & 33 \\
Control & 110 & 74 & 36 & & 184 & 36 \\
$\chi^{2}$ & & & 0.19 & & \multicolumn{2}{c}{0.16} \\
$\mathrm{p}$ & & & $>0.05$ & & \multicolumn{2}{c}{$>0.05$} \\
\hline
\end{tabular}

was significantly higher than that in the control group $(111.95 \pm 17.15 \%)$ and the difference was statistically significant $(\mathrm{t}=11.69, \mathrm{p}<0.05)$. In the experimental group, no significant difference was identified between the plasma vWF levels of males $(140.41 \pm 20.05 \%)$ and females $(143.55 \pm 21.22 \%$; $\mathrm{t}=0.7957, \mathrm{p}>0.05$ ). Similarly, in the control group, no significant difference was identified between the plasma vWF levels of males $(114.21 \pm 17.22 \%)$ and females $(108.80 \pm 16.72 \%$; $\mathrm{t}=1.644, \mathrm{p}>0.05$; Table I). The mean plasma vWF level of males across the experimental and control groups was $(127.10 \pm 22.77 \%)$ and this was not significantly different from that of the females in the two groups $(126.56 \pm 25.85 \%$; $\mathrm{t}=0.1679, \mathrm{p}>0.05$ ).

Plasma $v$ WF levels for different test groups and genotypes. The experimental and control groups had 69 total cases of genotype AG with a mean plasma vWF level of $134.68 \pm 32.05 \%$ and 151 cases of genotype GG with a mean plasma vWF level of $123.29 \pm 18.07 \%$. The mean plasma levels of vWF of genotype AG in the experimental and control groups were significantly higher than those of genotype GG $(t=3.329, p<0.05)$. In the experimental group, there were 33 cases of genotype AG with a plasma vWF level of $161.53 \pm 21.52 \%$ and 77 cases of genotype GG with a plasma vWF level of $133.32 \pm 12.95 \%$. The plasma level of vWF of genotype AG in the experimental group was significantly higher than that of genotype GG $(t=8.488, p<0.05)$. In the control group, there were 36 cases of genotype AG with a mean plasma vWF level of $110.07 \pm 18.05 \%$ and 74 cases of genotype GG with a mean plasma vWF level of $112.86 \pm 16.74 \%$; the difference between the genotypes was not statistically significant $(t=0.80, \mathrm{p}>0.05)$. The plasma $\mathrm{vWF}$ levels of the two genotypes in the experimental group were significantly higher than the corresponding values in the control group ( $\mathrm{p}<0.05$; Table II).

Comparison of genotype and allele frequency. No statistically significant differences in the distribution of the two genotypes between the experimental and control groups were observed $\left(\chi^{2}=0.19, p>0.05\right)$. Furthermore, no statistically significant differences were observed in the allele frequency distribution between the experimental and control groups $\left(\chi^{2}=0.16\right.$, $\mathrm{p}>0.05$ ). In the experimental group, the frequencies of alleles $\mathrm{G}$ and $\mathrm{A}$ were 85 and $15 \%$, respectively; in the control group, the frequencies of alleles $\mathrm{G}$ and $\mathrm{A}$ were 83.63 and $16.34 \%$, respectively (Table III). 
Table IV. Correlation between blood group and mean plasma von Willebrand factor (vWF) levels.

\begin{tabular}{lcccc}
\hline Group & $\begin{array}{c}\text { Blood } \\
\text { group }\end{array}$ & $\mathrm{n}$ & $\begin{array}{c}\text { Mean vWF } \\
\text { level (\%) }\end{array}$ & SD \\
\hline Control & $\mathrm{A}$ & 23 & 118.82 & 18.86 \\
& $\mathrm{~B}$ & 31 & 114.61 & 16.77 \\
& $\mathrm{AB}$ & 28 & 116.07 & 15.13 \\
& $\mathrm{O}$ & 28 & 99.24 & 11.05 \\
Experimental $^{\mathrm{b}}$ & $\mathrm{A}$ & 27 & 141.38 & 21.31 \\
& $\mathrm{~B}$ & 30 & 139.52 & 15.76 \\
& $\mathrm{AB}$ & 21 & 141.76 & 21.14 \\
& $\mathrm{O}$ & 32 & 144.25 & 23.86 \\
& & & &
\end{tabular}

$\mathrm{SD}$, standard deviation. ${ }^{\mathrm{a}} \mathrm{p}<0.05$ vs. blood types $\mathrm{A}, \mathrm{B}$ and $\mathrm{AB}$ within the control group; ${ }^{b} \mathrm{p}<0.05$, vs. the control group.

Correlation between different blood groups and plasma $v W F$. In the experimental group, the plasma vWF levels of blood types $\mathrm{A}, \mathrm{B}, \mathrm{AB}$ and $\mathrm{O}$ were significantly higher than the corresponding plasma levels in the control group $(p<0.05)$. However, no significant difference in plasma vWF levels was observed among the four blood types within the experimental group. In the control group, the plasma vWF levels of the subjects with blood type $\mathrm{O}$ were significantly lower than those of subjects with blood types A, B and AB ( $p<0.05$; Table IV).

\section{Discussion}

Previous studies have suggested that vWF is only synthesized by endothelial cells, is secreted into the circulation and has key effects on the formation of coronary thrombosis (9). Plasma vWF is now considered to be a marker of arterial endothelial injury and dysfunction and impacts the pathogenesis of coronary heart disease $(5,10)$. Current research suggests that vWF levels are related to coronary heart disease via the physiological functions of vWF proteins, but other research suggests a limited correlation between $\mathrm{vWF}$ and coronary heart disease (11). It is possible that particular aspects of vWF structure and function are related to heart disease and that a more detailed molecular analysis and epidemiology assessments are warranted.

Our results show that the plasma vWF levels of patients with coronary heart disease are significantly elevated compared with those of the normal population; this is essentially consistent with previous results obtained across demographically diverse populations (12). The plasma vWF levels of two genotypes (AG and GG) in the experimental group were higher than their corresponding levels in the control group. The results may be associated with a higher risk of vascular endothelial injury in patients with coronary heart disease, resulting in more vWF being released by the endothelial cells into the plasma (13).

Notably, the results show that overall, vWF gene polymorphism at the A1381T site is not associated with coronary heart disease. This finding may be caused by the limited sample size and needs to be evaluated in a larger cohort. However, the plasma vWF levels in the patients with the AG genotype were higher than those in the patients with the GG genotype among all 220 cases (experimental and control groups), but no statistically significant difference was observed between the two genotypes within the normal group. The current sample size was not sufficiently large to determine the specific correlation of plasma vWF with genotype AG and coronary heart disease, but this would be a worthwhile subject for subsequent studies.

Our study also found that the plasma vWF levels of patients with coronary heart disease and blood types A, B, $\mathrm{AB}$ and $\mathrm{O}$ were significantly higher than those of the normal population. However, no statistically significant differences were observed in the vWF levels among the four blood types in the patients with coronary heart disease. The plasma vWF levels of the normal population with blood type $\mathrm{O}$ were significantly lower than those of the other blood types. A previous study has shown that the ADAMTS13 metalloproteinase is able to inactivate plasma vWF by hydrolysis (14), while glycophorin glycosyltransferase is able to inhibit the hydrolysis of the metalloproteinase for vWF. There is a congenital lack of the relevant transferase in blood type $\mathrm{O}$. Therefore, the increased hydrolysis of vWF will significantly reduce the plasma levels of vWF (15). Accordingly, our results in the normal population are consistent with this known mechanism, but this association appears to be affected in the subjects with coronary heart disease. The reasons for this difference require further study.

In brief, the current results show that a polymorphism of the vWF gene at the A1381T site is not associated with coronary heart disease. However, vWF polymorphism at the A1381T site, blood type and coronary heart disease status all affected plasma vWF levels. Further studies in larger cohorts are required to ascertain which polymorphisms of the vWF gene are able to predict the risk of heart disease.

\section{Acknowledgements}

This study was supported by the Key Science and Technology Project of Henan Province (No. 112102310180).

\section{References}

1. Terraube V, O'Donnell JS and Jenkins PV: Factor VIII and von Willebrand factor interaction: biological, clinical and therapeutic importance. Haemophilia 16: 3-13, 2010.

2. Nair SC, Viswabandya A and Srivastava A: Diagnosis and management of von Willebrand disease: a developing country perspective. Semin Thromb Hemost 37: 587-594, 2011.

3. Othman M: Platelet-type von Willebrand disease: a rare, often misdiagnosed and underdiagnosed bleeding disorder. Semin Thromb Hemost 37: 464-469, 2011.

4. Bowen DJ and Collins PW: An amino acid polymorphism in von Willebrand factor correlates with increased susceptibility to proteolysis by ADAMTS13. Blood 103: 941-947, 2004.

5. Szántó T, Schlammadinger A, Staelens S, et al: The A/T1381 polymorphism in the A1-domain of von Willebrand factor influences the affinity of von Willebrand factor for platelet glycoprotein Ibalpha. Thromb Haemost 98: 178-185, 2007.

6. Simon D, Paludo CA, Ghisleni GC, Manfroi WC and Roisenberg I: Association studies between $-1185 \mathrm{~A} / \mathrm{G}$ von Willebrand factor gene polymorphism and coronary artery disease. Braz J Med Biol Res 36: 709-714, 2003.

7. van der Meer IM, Brouwers GJ, Bulk S, et al: Genetic variability of von Willebrand factor and risk of coronary heart disease: the Rotterdam Study. Br J Haematol 124: 343-347, 2004. 
8. Panda DK, Miao D, Bolivar I, et al: Inactivation of the 25-hydroxyvitamin D 1alpha-hydroxylase and vitamin D receptor demonstrates independent and interdependent effects of calcium and vitamin D on skeletal and mineral homeostasis. J Biol Chem 279: 16754-16766, 2004.

9. Klemm T, Mehnert AK, Siegemund A, et al: Impact of the Thr789Ala variant of the von Willebrand factor levels, on ristocetin co-factor and collagen binding capacity and its association with coronary heart disease in patients with diabetes mellitus type 2. Exp Clin Endocrinol Diabetes 113: 568-572, 2005.

10. Sedding D, Daniel JM, Muhl L, et al: The G534E polymorphism of the gene encoding the factor VII-activating protease is associated with cardiovascular risk due to increased neointima formation. J Exp Med 203: 2801-2807, 2006.

11. Bray PF, Mathias RA, Faraday N, et al: Heritability of platelet function in families with premature coronary artery disease. $\mathrm{J}$ Thromb Haemost 5: 1617-1623, 2007.
12. Kumari M, Marmot $\mathbf{M}$ and Brunner E: Social determinants of von willebrand factor: the Whitehall II study. Arterioscler Thromb Vasc Biol 20: 1842-1847, 2000

13. Hamaad A, Sosin MD, Blann AD, Lip GY and MacFadyen RJ: Markers of thrombosis and hemostasis in acute coronary syndromes: relationship to increased heart rate and reduced heart-rate variability. Clin Cardiol 32: 204-209, 2009.

14. Rios DR, Carvalho MG, Figueiredo RC, et al: ADAMTS13 and von Willebrand factor in patients undergoing hemodialysis. J Thromb Thrombolysis, Feb 2, 2012 (Epub ahead of print).

15. Rios DR, Fernandes AP, Figueiredo RC, et al: Relationship between ABO blood groups and von Willebrand factor, ADAMTS13 and factor VIII in patients undergoing hemodialysis. J Thromb Thrombolysis 33: 416-421, 2012. 